\title{
V-notch to Prevent Sliding of Crimpoble Hook
}

\author{
Dr Rajesh Gyawali,, Dr Prabhat Ranjan Pokharel,,2 Dr Gunjan Kumar Shrestha,3 Dr Jamal Giri4 \\ 1.AAssistant Professor, 2Associate Professor, Department of Orthodontics, \\ B P Koirala Institute of Health Sciences, Dharan, Nepal \\ 3Private Practitioner, Kathmandu, Nepal
}

\section{ABSTRACT}

En-mass retraction of anterior teeth most commonly involves the use of crimpable hooks which often dislodge when retracting force is applied. A V-notch distal to the hook may prevent such sliding when sandblasting and dental adhesives are not available.

Keywords: crimpable hook, retraction, sliding, V-notch

\section{INTRODUCTION}

Most of the orthodontic treatment involves the retraction of anterior teeth. We use soldered hooks or crimpable hooks to the archwire for applying force. The disadvantage of soldering is that it is time consuming, requires laboratory set up and may anneal the archwire.' So crimpable hooks are often used which is quick and easy, can also be crimped intraorally.

The problem encountered with crimpable hooks is that excessive force can cause gabling leading to unwanted force into the wire whereas less force may lead to dislodgement of the hook during retraction. ${ }^{2}$ To prevent dislodgement of the hook, tungsten carbide coating or sandblasting along with the use of dental adhesives have been tried. ${ }^{1,3}$

\section{TECHNIQUE}

We present a simple method to prevent dislodgement of the hook during retraction. A V-shaped notch is placed on the archwire just distal to crimpable hook (Figure 1 \& 2). The ' $V$ ' should be made as narrow as possible so that it occupies minimum mesio-distal dimension. A large $V$ notch may interfere with the bracket distal to the hook. This V-notch prevents sliding of the hook along the archwire during retraction of the anterior teeth.
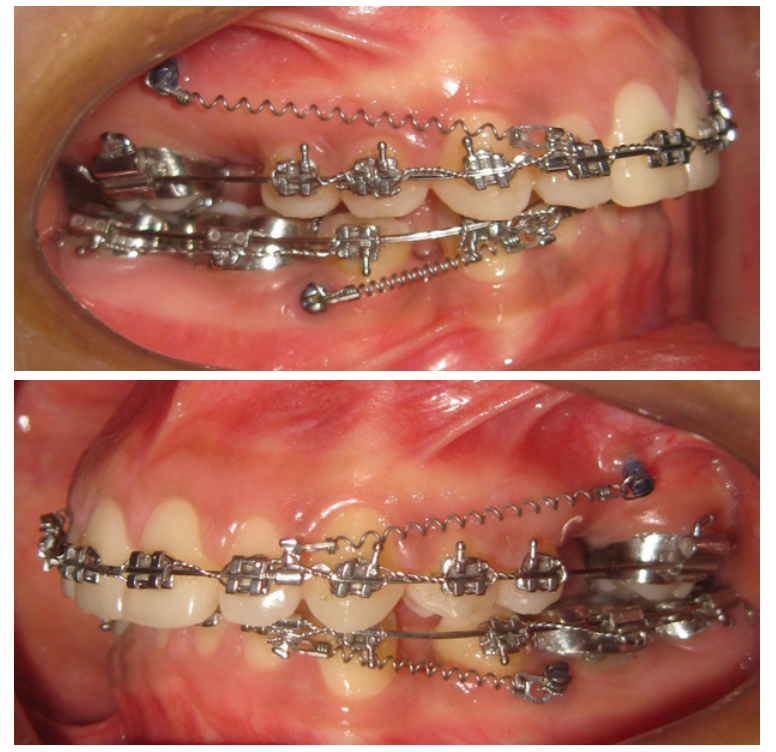

Figure.1, 2: V-notch distal to crimpable hook between lateral incisor and canine

\section{DISCUSSION}

There are various ways by which we can prevent sliding of crimpable hook. Making a $V$-notch needs archwire removal but is useful when we do not have the facility of sandblasting and dental adhesives.

\section{OJN}

\section{REFERENCES}

1. Johal A, Harper CR, Sherriff M. Properties of crimpable archwire hooks: A laboratory investigation. European J Orthodontics 1999; $21(6): 679-83$.

2. Evans R, Jones M. Laboratory evaluation of surgical ball hook crimping pliers. Int J Adult Orthod Orthognath Surg 1990; 6 (1):57-60.

3. Johal A, Loh S, Heng JK. A clinical investigation into the behavior of crimpable archwire hooks. J Orthod 2001; 28(3):203-6. 